\title{
Improvement of Critical Heat Flux Performance by Wire
}

\section{Spacer}

\author{
Dan Tri Le ${ }^{1}$ and Minoru Takahashi ${ }^{2}$ \\ 1. Department of Nuclear Engineering, Tokyo Institute of Technology, Tokyo N1-18, 2-12-1, Japan \\ 2. Research Laboratory for Nuclear Engineering, Tokyo Institute of Technology, Tokyo N1-18, 2-12-1, Japan
}

Received: July 27, 2015 / Accepted: September 07, 2015 / Published: October 31, 2015.

\begin{abstract}
In order to investigate the coolability of a tight lattice core in BWR (boiling water reactors), an experiment of CHF (critical heat flux) was conducted using a single heater pin flow channel with and without a wire spacer with the mass flux ranged from $200 \mathrm{~kg} /\left(\mathrm{m}^{2} \cdot \mathrm{s}\right)$ to $600 \mathrm{~kg} /\left(\mathrm{m}^{2} \cdot \mathrm{s}\right)$, the inlet temperature from $50{ }^{\circ} \mathrm{C}$ to $90{ }^{\circ} \mathrm{C}$ at the pressure of $0.1 \mathrm{MPa}$. The results of CHF values were compared between two different types of heater pin with and without the wire spacer. The heat removability of flow channel was improved by the wire spacer in comparison with the heater pin flow channel without the wire spacer. The CHF value was higher in the heater pin channel with the wire spacer than in that without the wire spacer.
\end{abstract}

Key words: Critical heat flux, tight lattice core, boiling two-phase flow, wire spacer.

\section{Nomenclature}

$d$
$D$
$D_{h e}$
$D_{h y}$
$d_{\text {wire }}$
$G$
$H$
$L$
$p$
$q_{C H F}$
$W$
$x$
$Z$

Greek letters

$\delta$

gap size (m)

Abbreviations

$\begin{array}{ll}\text { BWR } & \text { boiling water reactor } \\ \text { CHF } & \text { critical heat flux } \\ \text { LWR } & \text { light water reactor }\end{array}$

Corresponding author: Dan Tri Le, professor, research field: thermal hydraulic in nuclear reactor. E-mail: letridan.aa@m.titech.ac.jp.

\section{Introduction}

LWR (light water reactors), particularly BWR (boiling water reactors) core could have a higher conversion ratio nearly equal to unity by reducing moderator-fuel ratio [1]. In order to reduce the moderator to fuel ratio, tight lattice core with smaller coolant volume ratio compared with a normal core is one of the solutions. To be able to have a harder neutron spectrum event in the LWR, it is well known that, the tight lattice core with the pitch to diameter ratio, $P / d$, of nearly 1.09 [2] and 1.06 [3], which has the gap size distance of $1.3 \mathrm{~mm}$ and $0.9 \mathrm{~mm}$, respectively, can be used. These values were much smaller than those of conventional LWR [4].

The use of wire spacers is more suitable for the tight lattice core than the use of grid spacers. However, from thermal-hydraulic point of view, coolability or heat removability is one of key issues for the feasibility of the tight lattice core with the wire spacer because of the small flow area which is related with the small value of rod-to-rod gap. Besides, the most important feature of coolability of tight lattice core is 
the CHF (critical heat flux).

The study on the effect of gap size on CHF was well investigated by means of experiment in tight rod bundle with grid spacer [5]. From the results, the CHF values become lower with smaller gap size at the same mass flux.

In the previous study [6], the results of experiment performed using Freon-12 indicated the CHF in the hexagonal rod bundle with wire spacers was higher than that with grid spacers at low quality conditions. Then, CHF in water flow was evaluated by means of the fluid-to-fluid scaling law [7].

The effect of wire spacer on the promotion of $\mathrm{CHF}$ has been investigated for conventional fuel rod arrangement and for the round tube channel $[8,9]$. The beneficial effect of circular shape wire on thermal hydraulic performance was made clear in the previous study [10].

There have been some studies on CHF in tight lattice core so far. Nevertheless, experimental data on the CHF for the tight lattice core with wire spacers are still limited. Thus, the critical heat flux or burnout phenomenon in tight lattice core with wire spacers is one of the most important studies for such kind of fuel assembly.

Therefore, in the present study, effect of circular shape wire spacer on the enhancement of CHF for the case of tight lattice arrangement was investigated by means of CHF experiment for single pin test section with a wire spacer with three difference values of gap size were chosen: $1.1,1.5,2.0 \mathrm{~mm}$ to cover the range at which the conversion ration could be nearly equal unity.

\section{Experimental Apparatus and Procedure}

\subsection{Experimental Apparatus}

Fig. 1 shows the experimental apparatus of a water circulation loop. It consists of the water tank, the circulation pump, the pre-heater, the orifice flow meter and the CHF test section. The inlet of the test section was $4,200 \mathrm{~mm}$ far from the outlet of the pre-heater so the water temperature is constant prior to get into the

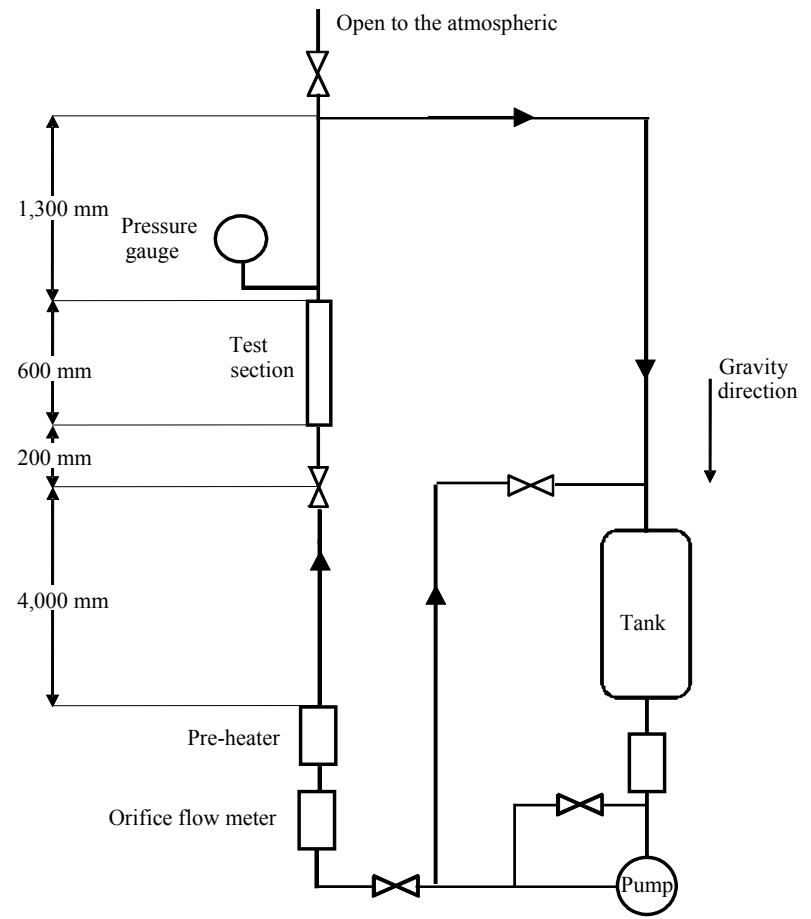

Fig. 1 Experimental apparatus.

test section. The water flowed from the water tank through the circulation pump and the pre-heater and entered the test section. The valve which is located at the top of the apparatus was kept open to the air to be able to keep the system pressure equal to the atmospheric pressure.

\subsection{Test Section}

Fig. 2a shows the CHF test section oriented vertically. The main parts of the test section are the heater pin, the upper and bottom copper electrodes, the glass tube, the thermocouples and the wire spacer in case of experiment for a heater pin with a wire spacer. The heater pin was directly Joule-heated by a direct current electrically. The materials of the glass tube used were Pyrex glass and crystal glass.

The heater pin was made of a thin stainless steel tube with an outer diameter, $d$, of $8 \mathrm{~mm}$ and a length of $420 \mathrm{~mm}$. It was connected to the copper electrodes at both ends by silver soldering. In the connection, the electrodes were inserted into the inside of the stainless steel tube in the depth of $10 \mathrm{~mm}$ before the soldering. Therefore, the heated length of the heater pin tube with a thin wall, 
$L$, was $400 \mathrm{~mm}$. On the other hand, the length to diameter ratio, $L / d$, of around 50 was large enough to suppress the effect of heated length on CHF [8]. The axial coil pitch of the wire, $H$, is the axial distance over which the wire completely wraps around the heater pin as shown in Fig. 2a. The axial pitch of the wire spacer, $H$, was set with two different values $100 \mathrm{~mm}$ and $200 \mathrm{~mm}$. For this two different values of the axial pitch, the value of $H / d$ less than 50 was the upper limit of the wire correlation for both $\mathrm{CHF}$ and pressure drop [8].

The cross section of the flow channel is shown in Fig. 2b. The spacer was electrically insulated from the heater pin. Fig. $2 \mathrm{c}$ shows the wire spacer made of a Teflon tube in which a stainless steel wire was inserted. Gap size, $\delta$, is the distance from the outer surface of heater pin to the inner surface of the glass tube as shown in Fig. 2b. For the rod diameter of $8 \mathrm{~mm}$, three different values of gap size were chosen: $1.1,1.5$ and $2.0 \mathrm{~mm}$. By changing the rod diameter, wire diameter and glass inner diameter, we could change the size of the gap.

The direct Joule-heating of the heater pin provided an uniform heat flux on the heater pin surface. The maximum power and current of the power in this experiment were $15 \mathrm{~kW}$ and $500 \mathrm{~A}$, respectively.

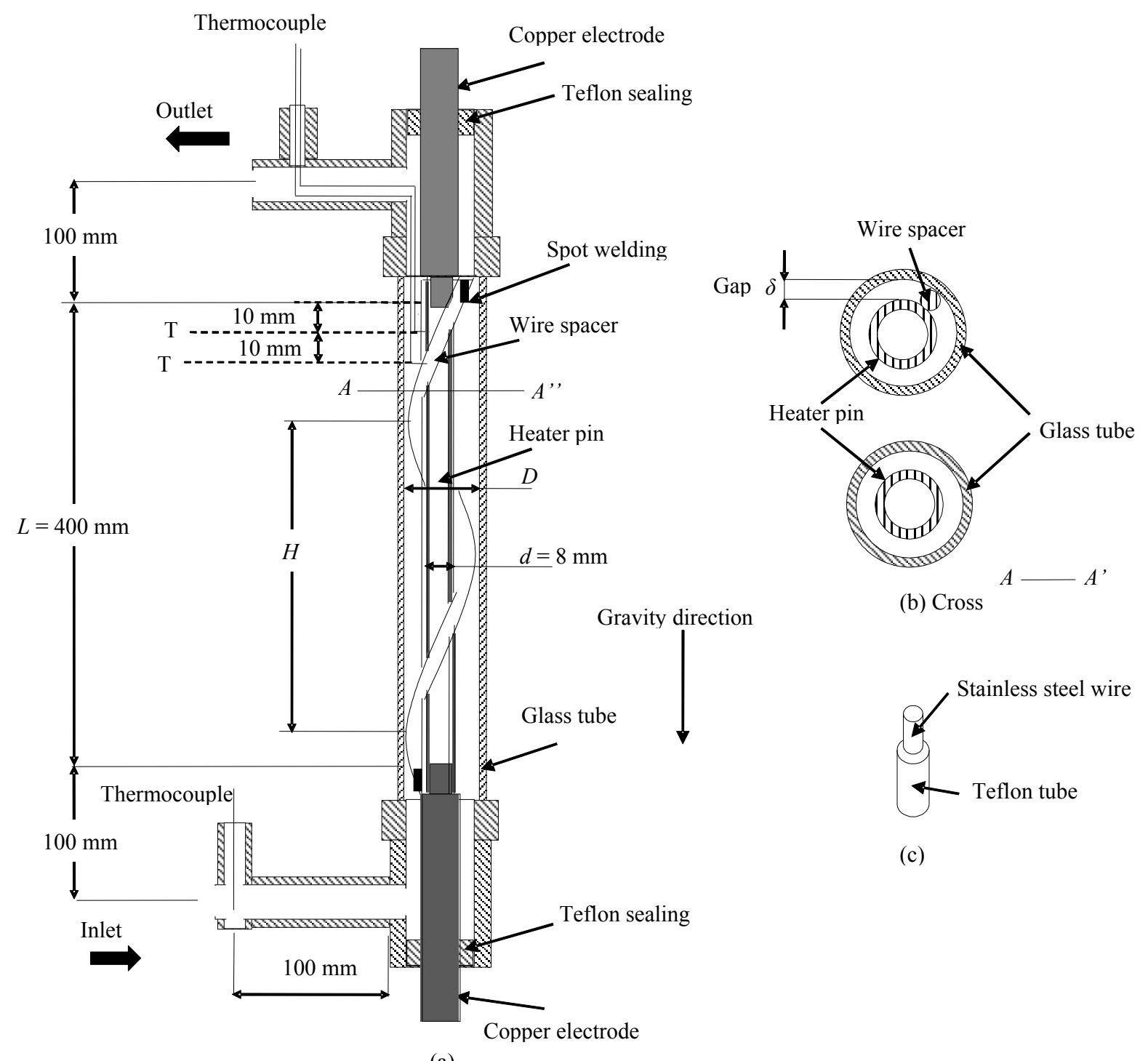

Fig. 2 Test section: (a) test section; (b) cross section of flow channel with wire and without wire spacer; (c) wire structure. 
To detect a sudden temperature rise on the heater pin surface at the CHF condition and quickly shutdown the heating power, type $\mathrm{K}$ thermocouple elements with diameter of $100 \mu \mathrm{m}$ were used for the surface heater pin temperature measurement. Fig. 2a shows that, the ends of the thermocouple elements were spot-welded to the surface to be hot junction at positions of $20 \mathrm{~mm}$ and $10 \mathrm{~mm}$ upstream from the downstream end of the heated length, being marked as $\mathrm{T} 1$ and $\mathrm{T} 2$, respectively. The effect of thermocouples on the CHF behavior can be neglected because its diameter is very small compared with the flow area.

Since the heater pin was directly heated by the current, the three points junction technique of thermocouple was used for compensation of voltage induced by the current between two point junctions.

In order to recognize the location of the reaching to the CHF, the position indications were written on the outside surface of the glass tube. By using thermocouples, the length indications and the camera, the positions of burnout or the arrival to the CHF were recognized.

\subsection{Experimental Conditions}

The experimental parameters and conditions are given in Table 1. Parameters in the experiment were the existence of the wire spacer, the gap size and the axial coil pitch of the wire, and the mass flux.

In order to investigate the effect of a wire spacer on CHF, the CHF experiments for both case of heater pin with and without a wire spacer were performed under the same mass flux condition. On the other hand, to be able to consider the effect of gap size on $\mathrm{CHF}$, the experiments at the same mass flow rate were chosen.

\subsection{Experimental Procedure and Measurement Items}

The water from the water tank was circulated in the loop by using the circulation pump. Water was heated up by the pre-heater before starting the experiment. The water in the water circulation loop was degassed initially by boiling the water in the test section for a

Table 1 Experimental condition.

\begin{tabular}{|c|c|c|c|c|c|c|c|}
\hline Parameter & $\begin{array}{l}\text { Run No.1 } \\
\text { with wire }\end{array}$ & $\begin{array}{l}\text { Run No.2 } \\
\text { without wire }\end{array}$ & $\begin{array}{l}\text { Run No.3 } \\
\text { with wire }\end{array}$ & $\begin{array}{l}\text { Run No.4 } \\
\text { with wire }\end{array}$ & $\begin{array}{l}\text { Run No.5 } \\
\text { with wire }\end{array}$ & $\begin{array}{l}\text { Run No.6 } \\
\text { with wire }\end{array}$ & $\begin{array}{l}\text { Run No.7 } \\
\text { with wire }\end{array}$ \\
\hline $\begin{array}{l}\text { Inner diameter of glass } \\
\text { tube, } D(\mathrm{~mm})\end{array}$ & 12 & 12 & 11 & 12 & 11 & 10.2 & 11 \\
\hline Gap size, $\delta(\mathrm{mm})$ & 2.0 & 2.0 & 1.5 & 2.0 & 1.5 & 1.1 & 1.5 \\
\hline Wire diameter, $d_{w}(\mathrm{~mm})$ & 1.79 & - & 1.4 & 1.79 & 1.4 & 1.06 & 1.4 \\
\hline Wire axial pitch, $H(\mathrm{~mm})$ & 200 & - & 200 & 200 & 200 & 200 & 100 \\
\hline Mass flux, $G\left(\mathrm{~kg} /\left(\mathrm{m}^{2} \cdot \mathrm{s}\right)\right)$ & 400 & 400 & 658 & - & - & - & - \\
\hline Mass flow rate, $W(\mathrm{~kg} / \mathrm{s})$ & - & - & - & 0.018 & 0.018 & 0.018 & 0.018 \\
\hline $\begin{array}{l}\text { Hydraulic diameter of } \\
\text { flow channel, } D_{h y}(\mathrm{~m})\end{array}$ & 0.0035 & 0.004 & 0.0027 & 0.0035 & 0.0027 & 0.002 & 0.0027 \\
\hline Pressure, $p(\mathrm{MPa})$ & 0.1 & 0.1 & 0.1 & 0.1 & 0.1 & 0.1 & 0.1 \\
\hline \multirow{10}{*}{ Inlet temperature $(\mathrm{K})$} & 335.3 & 334.5 & 336.9 & 338 & 331 & 337.5 & 330.5 \\
\hline & 336.5 & 339.7 & 342.1 & 343 & 331.5 & 338 & 340.4 \\
\hline & 343.4 & 345.2 & 346 & 348.6 & 337 & 341.4 & 350 \\
\hline & 344.9 & 347.8 & 349.2 & 348.8 & 342 & 355.3 & 350.5 \\
\hline & 347.2 & 353.3 & 351.5 & 354.7 & 349.5 & 366 & 356 \\
\hline & 349.6 & 361.5 & 357.5 & - & 353 & - & - \\
\hline & 355 & 362.3 & 359.6 & - & 357 & - & - \\
\hline & 357.8 & - & - & - & 367.6 & - & - \\
\hline & 361.5 & - & - & - & - & - & - \\
\hline & 365.9 & - & - & - & - & - & - \\
\hline
\end{tabular}


while until air dissolved in the water was removed sufficiently.

During the experiment, the water flow rate was kept constant. The flow resistance at the inlet valve of the test section was kept high enough to suppress the instability of flow rate due to the instability of pressure drop of two-phase flow in the test section. When the water temperature was kept constant at the inlet of the test section reached the desired value by controlling the pre-heater, the electric power to the heater pin in the test section was increased gradually by remote controlling.

Surface temperature of the heat pin was measured and recorded by using the thermocouples with the sampling frequency of $100 \mathrm{~Hz}$. The power of the heater pin was increased step by step until the surface temperature of the heater pin rapidly and suddenly increased because of reaching the CHF condition. Immediately after reaching the CHF condition, the power source was automatically shut down by the signal of sudden rise of surface temperature.

Fig. 3 shows the behaviors of the measured surface and inlet temperatures, voltage and current during the operation. It can be seen that, the inlet temperature was kept constant. The surface temperatures $\mathrm{T} 1$ and $\mathrm{T} 2$ increased slightly due to the increase of the electric power to the heater pin, and then suddenly the surface temperatures of the heater pin $\mathrm{T} 1$ and $\mathrm{T} 2$ rapidly increased. It was judged that, at this time, the burn-out took place or the heat flux reached the CHF.

The experimental data of the CHF were obtained in the range of mass flux and inlet temperature mentioned above with three different values of $\delta$ and two different values of wire pitch, $H$. The measurements were made under the boiling two-phase flow condition. The measurement accuracy of the heat flux value was high enough since it was determined from measured voltage and current. In order to keep the uncertainty of the results small, only the experimental data obtained under the condition which met the following requirements were chosen:
- The flow rate was stable during the experiment;

- The inlet temperature fluctuated within $1 \mathrm{~K}$.

\section{Results and Discussion}

\subsection{Comparison with Look up Table Data}

Following Fig. 4 [11, 12], the calculated values were obtained by using the CHF correlation with the rod-centered approach [11] and the 2006 CHF [12] look up table data. The results were close to the experimental results of heater pin without a wire spacer.

\subsection{Effect of Wire Spacer}

Fig. 5 shows the comparison of the CHF values of

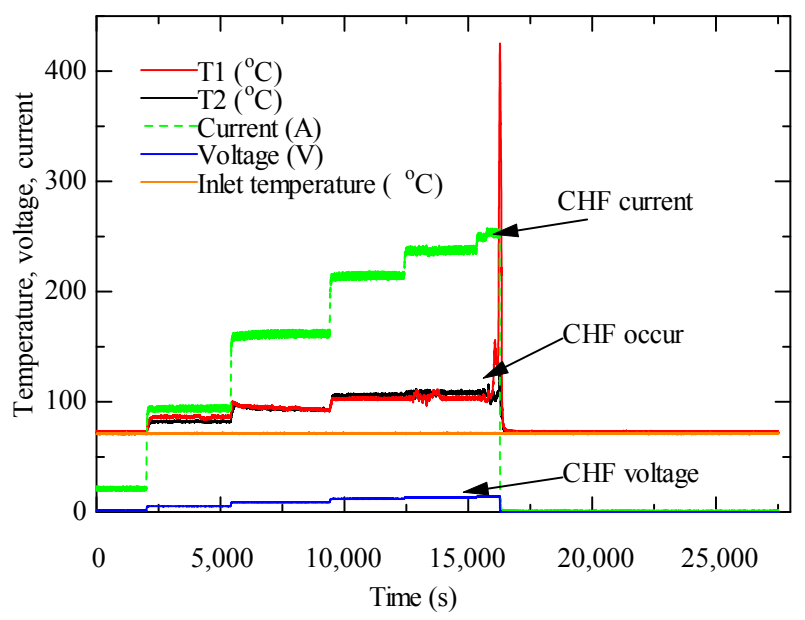

Fig. 3 Temperature behavior during the experiment.

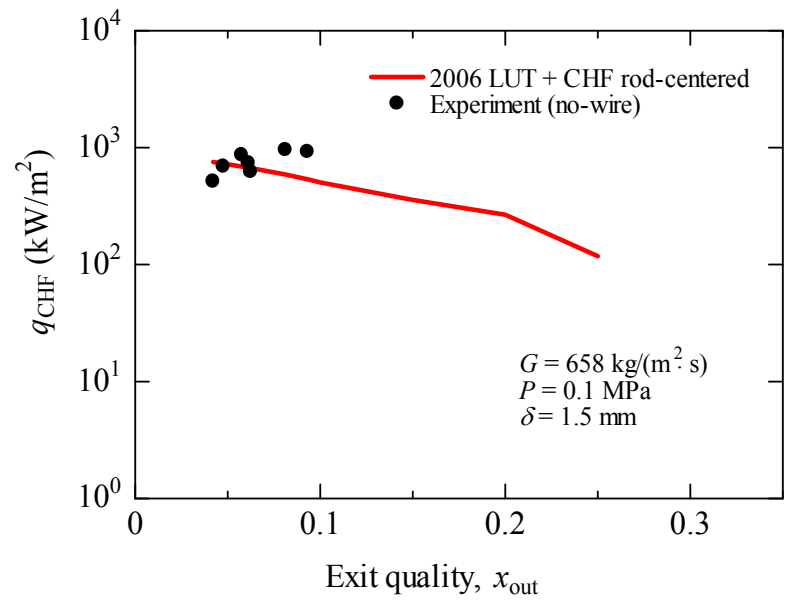

Fig. 4 Comparison of experimental results with the calculated results using $\mathrm{CHF}$ correlation for the rod-centered approach for the CHF look-up table. 


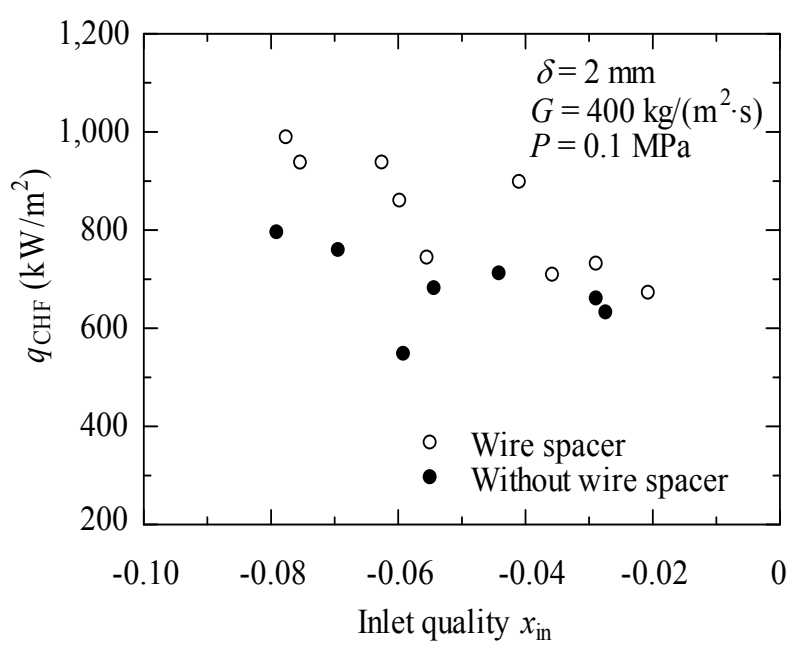

Fig. 5 Critical heat flux base on inlet condition.

single pin channels between with the wire spacer and without the wire spacer. It was found that, the CHF values in both types of heater pin decreased with the decrease of the inlet equilibrium steam quality, $x_{\mathrm{in}}$. However, the CHF values were higher in case of heater pin with the wire spacer than that in case of heater pin without the wire spacer. It could be explained by the enhancement of bubble removal from the heated surface due to the effect of wire and spiral flow. Compared with the work of Cheng and Müller [6], the results of the present study were obtained in smaller range of the quality from -0.1 to 0 . However, it can be seen that, the CHF values of wire type were still higher than those without wire type even if the inlet equilibrium steam quality was close to zero. Besides, the difference in the CHF values between heater pin with and without wire spacer was larger in lower qualities compared with the difference of CHF in higher qualities.

In furtherance of the investigation of CHF behavior under the effect of the wire spacer, the change in wire spacer size is needed. Therefore, the CHF experiment with different value of $\delta$ and $H$ was performed to deal with such kind of study. These experiments were performed under the same flow rate condition of the practical reactor rather than the same mass flux. From reactor design point of view, the consideration of the same water flow rate rather than the same mass flux is needed to be able to keep the best coolability for difference core design. Fig. 6 shows the comparison of the CHF values between three different values of gap size at the same flow rate. It can be seen that, at the same local quality, $x_{z}$, the CHF values were enhanced with the decrease of gap size under the same flow rate condition. In more detail, the CHF values were higher in case of smaller gap size and it was the highest in case of the smallest gap size. That is because the channel which has the smallest flow area has the highest mass flux at the same water mass flow rate which leads to the enhancement of CHF values. Moreover, there is an effect of the water film along the inner surface of the channel (glass tube) on CHF values. At the low quality region and bigger channel, this effect does not have the big influence on CHF value. However, at the high quality region and smaller gap size, the cold wall effect became higher. In detail, the vapor velocity was high in case of high quality region due to the high evaporation rate. Therefore, it may disturb the water film which flow along the inner surface of the channel and bring the drop let to the heated surface, which cause of increasing of droplet deposition rate. This phenomena lead to the increase of CHF values at high quality region. On the other hand, with the smaller gap size, the droplet concentration in the vapor phase also higher compared with it in case of bigger gap size. This is another reason which contributed for the increase of CHF values.

On the other hand, according to Fig. 6, the experiment with smaller gap size could reach higher CHF values and also could go to the higher local quality, $x_{z}$. Moreover, in case of bigger gap size ( $\delta=$ $2.0 \mathrm{~mm}$ ), the CHF value tended to decrease with the increase of quality. However, in case of flow channel with small gap size, the CHF values were nearly constant value or slightly increase with the increasing of quality.

Fig. 7 illustrates the CHF results in two different values of wire pitch, $H$. It can be seen that, the CHF values were nearly the same between two different 


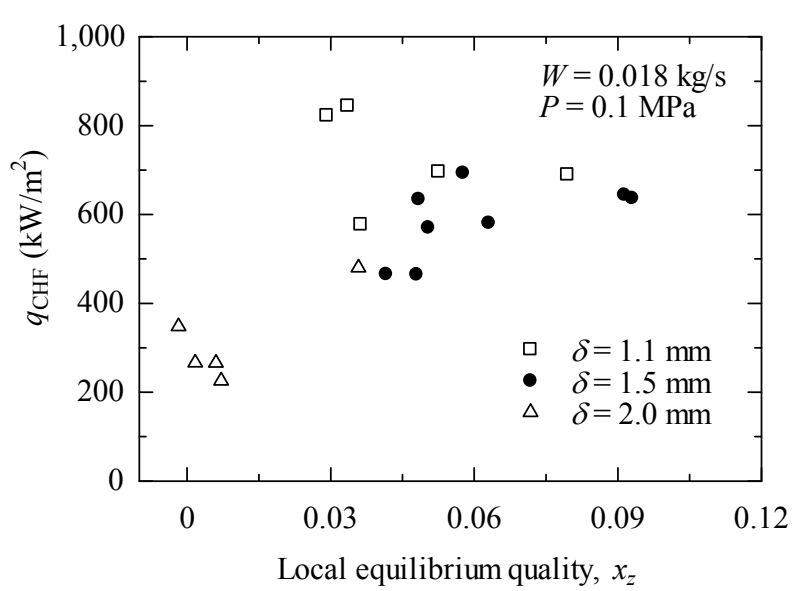

Fig. 6 Critical heat flux of three different values of gap size.

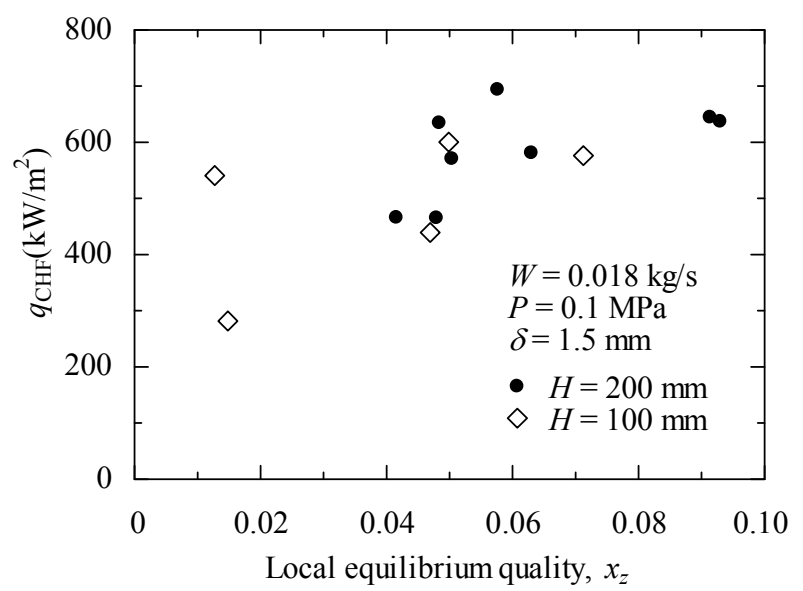

Fig. 7 Critical heat flux of two different values of wire pitch, $H$.

values of $H$. It can be explained that, there were two flow channels with two different values of wire pitch, velocity was the same. Since the velocity was the same, the mass flux was the same. Therefore, it is clear that, the axial pitch did not have a large influence on the CHF. However, it is necessary to consider about the pressure drop for the design purpose at the same time.

\subsection{Axial Position of $\mathrm{CHF}$}

The relation between the CHF values and the heated length to the position of arriving at CHF is shown in Fig. 8.

It is found that, at the same mass flow rate, $W$, the CHF occurred mostly in the downstream of the flow channel. Fig. 8 also shows the comparison of CHF position among three different values of gap size. In

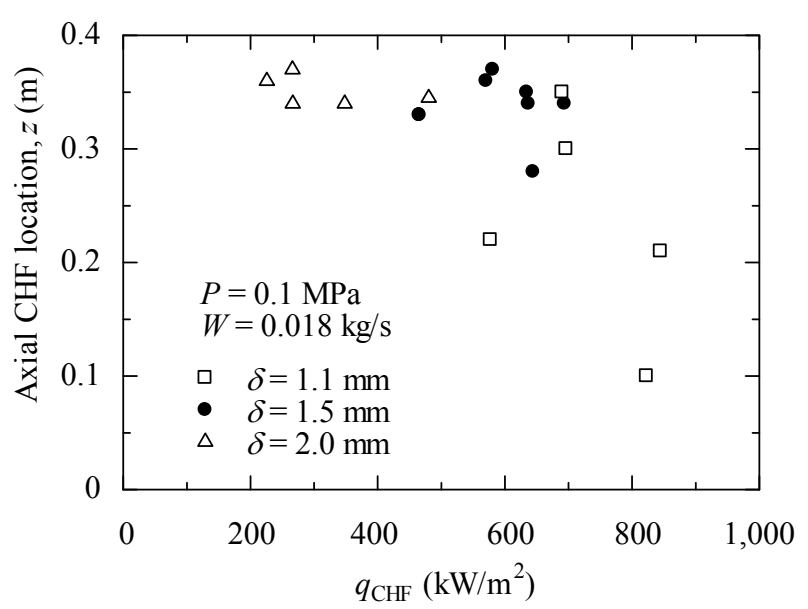

Fig. 8 Critical heat flux base on the heated length.

case of gap size of $1.5 \mathrm{~mm}$ and $2.0 \mathrm{~mm}$, the CHF positions were mainly at the downstream of flow channel. Therefore, the CHF in this case was principally caused by liquid film dry-out. On the other hand, with the smallest flow area, gap size of $1.1 \mathrm{~mm}$, there was the possibility of CHF occurring at the upstream of flow channel because of the high heat flux and high flow rate. According to the results, the $\mathrm{CHF}$ positions changed slightly with different values of the flow area or gap size. The CHF position tended to move from downstream to the upstream of the flow channel due to the decrease of gap size.

\section{Conclusions}

The CHF phenomena for the tight lattice fuel arrangement with the effect of wire spacer were investigated by mean of the experiment for single fuel pin with and without wire spacer and three difference values of gap size of $1.1,1.5,2.0 \mathrm{~mm}$. Besides, the effect of wire pitch was made clear by the experiment with two dissimilar wire pitch value of $100 \mathrm{~mm}$ and $200 \mathrm{~mm}$. The conclusions are as follows:

- The CHF in case of heater pin with circular shape wire was enhanced up to $25 \%$ compared with it in case of without wire space under the same flow condition. Therefore, the coolability or heat removability was enhanced by the existence of the wire spacer and spiral flow;

- With the same flow rate condition, the CHF 
values can be increased up to $100 \%$ with the decrease of gap size. Therefore, the flow channel with smaller gap size a higher coolability compared with the flow channel with larger gap size;

- The change in a pitch of wire, $H$, with two difference values of $100 \mathrm{~mm}$ and $200 \mathrm{~mm}$, did not have a large influence on the CHF if the mass flux was kept constant. The experiment data were nearly the same value even with two different cases of wire pitch.

\section{Acknowledgments}

The study was supported by Hitachi Nuclear Scholarship project. The authors would like to give the thank to Dr. Noriaki Inaba and Dr. Masatoshi Kondo for their discussion and Mr. Shoji Matsui for his assistance in the technical work.

\section{References}

[1] Sidik, P., Takaki, N., and Sekimoto, H. 2006. "Impact of Different Moderator Ratios with Light and Heavy Water Cooled Reactor in Equilibrium States." Annals of Nuclear Energy 33 (7): 561.

[2] Uchikawa, S., Okubo, T., Kugo, T., Akie, H., Takeda, R., Nakano, Y., Ohnuki, A., and Iwamura, T. 2006. "Conceptual Design of Innovative Water Reactor for Flexible Fuel Cycle (FLWR) and Its Recycle Characteristics." Journal of Nuclear Science and Technology 44 (3): 277-84.

[3] Sidik, P., Takaki, N., and Sekimoto, H. 2008. "Preliminary Study on Feasibility of Large and Small Water Cooled Thorium Breeder Reactor in Equilibrium Sates.” Progress in Nuclear Energy 50 (2-6): 320-4.

[4] Syeilendra, P. 2013. "Study on Hydrodynamic Model of Fuel Subassembly with Wire-Wrapped Rods for Nuclear Reactors." Doctoral dissertation, Tokyo Institute of Technology.

[5] Tamai, H., Kureta, M., Liu, W., Sato, T., Ohnuki, A., and Akimoto, H. 2007. "Gap Width Effect on Critical Power Based on Tight-Lattice 37-Rod Bundle Experiments." Journal of Nuclear Science and Technology 44 (1): 54-63.

[6] Cheng, X., and Müller, U. 1998. "Critical Heat Flux and Turbulent Mixing in Hexagonal Tight Rod Bundles." International Journal of Multiphase Flow 24 (8): 1245-63.

[7] Courtaud, M., Deruaz, R., and D'Aillon, L. G. 1988. “The French Thermal-hydraulic Program Addressing the Requirements of the Future Pressurized Water Reactors." Nucl. Technol. 80 (1): 73-82.

[8] Diller, P., Todreas, N., and Hejzlar, P. 2009. "Thermal-Hydraulic Analysis for Wire-Wrapped PWR Cores." Nuclear Engineering and Design 239 (8): 1461-70.

[9] Celata, G. P., Cumo, M., and Mariani, A. 1994. "Echancement of CHF Water Subcooled Flow Boiling Tubes Using Helically Coiled Wires." International Journal of Heat and Mass Transfer 37 (1): 52-67.

[10] Wasim, R, and Kwang, Y. K. 2008. "Effects of Wire-Spacer Shape in LMR on Thermal-Hydraulic Performance.” Nuclear Engineering and Design 238 (10): 2678-83.

[11] Doerffer, S., Groeneveld, D. C., Cheng, S. C., and Rudzinski, K. F. 1994. "A Comparison of Critical Heat Flux in Tubes and Annuli." Nuclear Engineering and Design 149 (1-3): 167-75.

[12] Groeneveld, D. C., Shan, J. Q., Vasić, A. Z., Leung, L. K. H., Durmayaz, A., Yang. J., Cheng, S. C., and Tanase, A. 2007. "The 2006 CHF Look-up Table." Nuclear Engineering and Design 237 (15-17): 1909-22. 